\title{
Activity-guided purification reveals quercetin as the most efficient cholinesterase inhibitor in wild strawberry (Fragaria vesca L.) and apricot (Prunus armeniaca L.) fruit extract
}

\author{
Dominik Szwajgier ${ }^{1}$, Kamila Borowiec ${ }^{1 *}$, Josef Zapp ${ }^{2}$ \\ ${ }^{1}$ Department of Biotechnology, Microbiology and Human Nutrition, University of Life Sciences in Lublin, Skromna 8, 20-704 Lublin, Poland, \\ ${ }^{2}$ Institut für Pharmazeutische Biologie, Universität des Saarlandes, Campus C2 3, 66123 Saarbrücken, Germany
}

\section{A B S TR A C T}

\begin{abstract}
Cholinesterase (ChE) inhibitors are commonly approved for the Alzheimer's disease therapy which should restore the original levels of acetylcholine in the brain. In this work, a suitable purification procedure of ChE inhibitors from wild strawberry (Fragaria vesca L.) and apricot (Prunus armeniaca L.) fruit is presented. Activity-guided purification was based on ultrafiltration $(0.2 \mu \mathrm{m} \rightarrow 5 \mathrm{kDa} \rightarrow 3 \mathrm{kDa})$ of water extract from fruit followed by preparative chromatography (Sephadex LH-20 and HPLC-C18) and analytical HPLC-C18. At every stage of purification, anti-ChE activity was measured in each fraction using Ellman's colorimetric method. The most active ChE inhibitor purified from both fruits was quercetin and the chemical structure was confirmed by infrared (IR) and proton nuclear magnetic resonance ( $\left.{ }^{1} \mathrm{H}-\mathrm{NMR}\right)$ spectroscopies. The fast purification procedure can be used for isolating phenolic ChE inhibitors from other fruits from the Rosaceae family.
\end{abstract}

Keywords: Apricot; Cholinesterase inhibitors; Chromatography; Quercetin; Wild strawberry.

\section{INTRODUCTION}

Alzheimer's disease (AD) is a severe disease in persons aged 65 or older involving the loss of cholinergic neurons (Whitehouse et al., 1981), manifested by an imbalance of acetylcholinesterase (AChE) and butyrylcholinesterase (BChE) activity and the deposition of intra- and extracellular $\beta$-amyloid in the brain tissue (Rao et al., 2007). The only commonly approved therapy for AD is based on a decrease of the activity of both enzymes which should restore the original levels of acetylcholine in the brain, as comprehensively discussed in the work of Dos Santos Picanco et al. (2018).

In the past, the high biological activity of wild strawberry (Fragaria vesca L.) fruit was attributed to the especially high phenolic content, resulting in antioxidant activity several times higher in comparison with strawberry ( $F$. ananassa) fruit (Scalzo et al., 2005). As early as 1956, Sondheimer and Karash (1956) showed that wild strawberry fruit is a rich source of pelargonidin 3-monoglucoside and cyanidin 3 -monoglucoside in the ratio of $1: 1$. Indeed, wild strawberry fruit contains a remarkably higher content of polyphenolic compounds than strawberry and Chilean white strawberry (F. chiloensis) (Cheel et al., 2007; Doumett et al., 2011). The consumption of wild strawberry fruit caused an elevated serum antioxidant activity in humans (Cao et al., 1998) and a high content of polyphenols (in comparison with 17 plants belonging to Asteraceae and Rosaceae families), extracts from wild strawberry fruits were outstanding anticoagulant factors (Pawlaczyk et al., 2009). Also, preparations from wild strawberry fruit exerted an anti-cancer effect in experimental rats (e.g., Carlton et al., 2001) and in cancer cell lines (e.g., Wedge et al., 2001).

Another polyphenol-rich fruit is apricot (Prunus armeniaca L.). Quercetin 3-rutinoside, kaempferol 3-rhamnosyl-hexoside, quercetin 3-acetyl-hexoside, cyanidin 3-rutinoside, cyanidin

\footnotetext{
*Corresponding author:

Kamila Borowiec, Department of Biotechnology, Microbiology and Human Nutrition, University of Life Sciences in Lublin, Skromna 8, 20-704 Lublin, Poland. E-mail: kamila.borowiec@up.lublin.pl
} 
3-glucoside, quercetin-3-O-rhamnoglucoside, kaempferol 3 -rutinoside, aglycons (+)-catechin, (-)-epicatechin, kaempferol and a wide range of phenolic acids (chlorogenic, neochlorogenic, caffeic, p-coumaric and ferulic acids) are the main polyphenols in apricot (Dragovic-Uzelac et al., 2005b, 2005b; Ruiz et al., 2005; Roussos et al., 2011).

In this work, we made an attempt to identify the main $\mathrm{AChE}$ and BChE inhibitor(s) from wild strawberry and apricot fruit extracts. For this purpose, we propose a convenient purification method based on chromatographic techniques.

\section{MATERIALS AND METHODS}

\section{Preparation of freeze-dried water extract}

Fruit $(1 \mathrm{~kg})$ was homogenized (Thermomix, Vorwerk, Wuppertal, Germany) at ambient temperature (4 min, at maximal speed). $1 \mathrm{~L}$ of distilled de-ionized (DDI) water was added followed by homogenization (4 min). After centrifugation (Sigma 4K15, Sigma Laboratory Centrifuges, Osterode am Harz, Germany; $30 \mathrm{~min}, 4{ }^{\circ} \mathrm{C}, 9000$ x g), the residue was homogenized with $0.5 \mathrm{~L}$ of DDI water (Thermomix), the sample was centrifuged (in the same manner) and the residue was once more extracted $(1 \mathrm{~L}$ of DDI water) followed by centrifugation as described above. All supernatants were collected (ca. $3 \mathrm{~L}$ ) and diluted with DDI water (extract: water 4:1 v: v) and ultrafiltered $\left(4^{\circ} \mathrm{C}: 0.2 \mu \mathrm{m} \rightarrow 5 \mathrm{kDa} \rightarrow 3 \mathrm{kDa}\right.$ cut-off, Vivaflow type 50 cartridges, Sartorius Stedim, Aubagne, France; Masterflex L/STM Economy Drive pumps, Cole-Palmer, Vernon Hills, IL, USA). The ultrafiltered sample was vacuum concentrated (approx. 5 -fold, $35^{\circ} \mathrm{C},-0,09 \mathrm{MPa}$ ) and freezedried $\left(-50{ }^{\circ} \mathrm{C}, 0.07-0.04 \mathrm{mBar}\right.$, FreeZone 2.5 system, Labconco, Kansas City, MO, USA).

\section{Preparative chromatography (Sephadex LH-20)}

Separation was performed in a glass Econo-Column $(5.0 \times 70 \mathrm{~cm}$, Bio-Rad, Hercules, CA, USA) in a BioLogic LP chromatograph (peristaltic pump, dynamic mixer, UV detector, 211 Fraction Collector, Bio-Rad). The column was equilibrated by $2 \mathrm{~L}$ of deionised water. A freeze-dried sample $(5 \mathrm{~g})$ was dissolved in DDI water $(30 \mathrm{~mL})$ and loaded onto the gel. Various chromatographic programs and eluents were used (optimization experiments not shown, personal communication). The final program was as follows: $0.2 \mathrm{~L}$ of DDI water followed by $1 \mathrm{~L}$ of $30 \%(\mathrm{v} / \mathrm{v})$ high performance liquid chromatography (HPLC) grade methanol in DDI water and $0.6 \mathrm{~L}$ of $50 \%(\mathrm{v} / \mathrm{v})$ HPLC grade methanol in DDI water (at $\left.0.25 \mathrm{~mL} / \mathrm{min}, 16^{\circ} \mathrm{C}\right)$. Each fraction $(2 \mathrm{~mL}$ ) was individually analysed $(\mathrm{n}=2)$ for the anti-AChE or anti-BChE activity, as described below. Active fractions were gathered, vacuum concentrated $\left(35^{\circ} \mathrm{C},-0,09 \mathrm{MPa}\right)$ and separated using the preparative HPLC system as described below.

\section{Preparative HPLC (C18)}

A BioLogic DuoFlow system (Bio-Rad) was used (BioLogic pumps, QuadTec UV-VIS detector, BioFrac fraction collector). A Knauer C18 column (Eurospher 100-5 C18, 250 × 20 mm, Knauer, Berlin, Germany) was used for separations of concentrated fractions obtained from Sephadex LH-20 (5 mL, 0.3 - $0.4 \mathrm{mg}$ total phenolic compounds $/ \mathrm{cm}^{3}$ measured as proposed by Folin and Ciocalteu, 1927). Various chromatographic programs and eluents were tested (detailed optimization experiments not presented, personal communication). The final gradient was composed of DDI water (A) and 100\% HPLC grade methanol (B): $0-10 \min 0 \% \mathrm{~B}, 10-14 \min 20 \rightarrow 30 \% \mathrm{~B}, 14$ $-30 \min 30 \% \mathrm{~B}, 30-33 \min 30 \rightarrow 90 \% \mathrm{~B}, 33-43 \min 90$ $\rightarrow 0 \% \mathrm{~B}, 43-50 \mathrm{~min} 0 \% \mathrm{~B}\left(10 \mathrm{~mL} / \mathrm{min}, 16^{\circ} \mathrm{C}\right)$. Detection was performed at $245 \mathrm{~nm}, 280 \mathrm{~nm}, 365 \mathrm{~nm}$ and $530 \mathrm{~nm}$. All signals were analysed using the BioLogic DuoFlow V.5.10 Build 2 program. Typically, ca. 250 fractions $(2 \mathrm{~mL})$ were obtained and the anti-ChE activity was measured in each fraction, as described below, after evaporation of methanol $\left(35{ }^{\circ} \mathrm{C},-0.09 \mathrm{MPa}\right)$. Selected separations were repeated approx. 20 times and corresponding fractions containing inhibitors were gathered and concentrated (approx. 15-fold, $35{ }^{\circ} \mathrm{C},-0.09 \mathrm{MPa}$ ). Active fractions (20-fold concentrated) were studied in analytical HPLC as described below.

\section{Analytical HPLC}

Fractions obtained from preparative HPLC were filtered using syringe filters $(0.45 \mu \mathrm{m}$, Merck Millipore, Darmstadt, Germany) and studied in a Knauer HPLC system (Smartline 100 pumps, dynamic mixer, $100 \mu \mathrm{l}$ loop, Retriever 500 fraction collector) with detection at $280,320,365$ or $520 \mathrm{~nm}$ (UV-VIS detector, Linear Instruments, Reno, NV, USA) coupled with the IF2 Knauer interface. The following C18 columns were tested during this study: Hypersil ODS-2 (250 mm x $4.6 \mathrm{~mm}, 5 \mu \mathrm{m}$, Thermo Scientific, Waltham, MA, USA), Hypersil Gold (150 mm x $4.6 \mathrm{~mm}, 5 \mu \mathrm{m}$, Thermo Scientific), Phenomenex Luna Phenyl-Hexyl (150 mm x $4.6 \mathrm{~mm}, 3 \mu \mathrm{m}$, Phenomenex, Torrance, CA, USA), Waters Symmetry $(250 \mathrm{~mm}$ x $4.6 \mathrm{~mm}, 5 \mu \mathrm{m}$, Waters Corp., Milford, MA, USA), LiChospher 100 RP18 (250 mm x $4.0 \mathrm{~mm}, 5 \mu \mathrm{m}$, Macherey-Nagel, Düren, Germany). For optimal separations, the Hypersil ODS-2 column was coupled in series with the LiChospher 100 RP18 column and corresponding precolumns (max. pressure $30 \mathrm{MPa}$ ). The final gradient was formed by DDI water (A) and $90 \%$ HPLC grade methanol in DDI water (B): $0-10 \mathrm{~min}$ $0 \% \mathrm{~B}, 10-70 \min 0-100 \% \mathrm{~B}, 70-76 \min 100 \% \mathrm{~B}$, $76-80100-0 \% \mathrm{~B}, 80-95 \mathrm{~min} 0 \% \mathrm{~B}(1 \mathrm{~mL} / \mathrm{min}$, room temperature). Drops corresponding to single peaks of compounds were manually directed to separate tubes of a fraction collector after the repeated injection of the same sample (typically 20-50 times). Signals 
were analysed using the Eurochrom 3.05 P5 program (2000 Basic Edition, Knauer). In the case of insufficient separation of a compound, the fraction was gathered after a number of consecutive injections and once more injected into HPLC. The anti-ChE activity of a fraction (isolated chromatographic peak) was measured after the evaporation of methanol in a vacuum evaporator $\left(35{ }^{\circ} \mathrm{C},-0.09 \mathrm{MPa}\right)$ or in a freeze-dryer. The obtained fractions were studied using infrared (IR) and proton nuclear magnetic resonance ( $\left.{ }^{1} \mathrm{H}-\mathrm{NMR}\right)$ spectroscopies.

\section{IR spectroscopy}

Analysis was performed in the Analytical Laboratory, Dept. of Chemistry (UMCS, Lublin, Poland). A Nicolet 8700A spectrometer was coupled with a Smart Orbit TR diamond ATR (ID: 090 - 9003, Thermo Scientific), in total single internal reflectance mode (Attenuated Total Reflectance). A potassium bromide beamsplitter (nominal spectral range: $7.800-350 \mathrm{~cm}^{-1}$ ) and deuterated triglycine)/potassium bromide detector (nominal spectral range: $12.500-350 \mathrm{~cm}^{-1}$ ) were used. The following parameters were used during the measurements: velocity of the scanning mirror 0.6329 , sampling 1.0000 , resolution 4.000 in the range of $400.1569-4000.1221$, number of scans 64 , length of measurement $90.13 \mathrm{~s}$, number of data points: 16672 , number of fast Fourier transform points 65536 , laser frequency $15798.0 \mathrm{~cm}^{-1}$, placement of interferogram peak 8192 , number of background scans 16, amplification of background 8.0, shutter 34.00. The enhanced synchronization protocol (ESP) mode with a system of dynamic justification was used. The OMNIC program was used for data processing and presentation (24-bit conversion of signals). Atmospheric correction, Happ-Genzel apodization and Mertz phase correction were applied.

\section{${ }^{1} \mathrm{H}-\mathrm{NMR}$ spectroscopy}

All ${ }^{1} \mathrm{H}-\mathrm{NMR}$ spectra were recorded in deuterated methanol with a Bruker Avance 500 NMR spectrometer (Rheinstetten, Germany) at $25^{\circ} \mathrm{C}$. The chemical shifts are relative to deuterated methanol at $3.30\left({ }^{1} \mathrm{H}-\mathrm{NMR}\right)$ in parts per million (ppm).

\section{Determination of anti-ChE activity}

The analysis was performed using a 96-well microplate reader (Tecan Sunrise, Grödig, Austria) based on the method of Ellman et al. (1961) with own modifications. The test solution was composed of $0.035 \mathrm{~mL}$ of acetylthiocholine (ATCh) or butyrylthiocholine (BTCh) $(1.5 \mathrm{mM} / \mathrm{L}), 0.005-0.035 \mathrm{~mL}$ of the studied sample, $0.02 \mathrm{~mL}$ of $\mathrm{AChE}$ (BChE) solution $(0.28 \mathrm{U} / \mathrm{mL})$ and $0.175 \mathrm{~mL}$ of $0.3 \mathrm{mM} / \mathrm{L} 5,5$ '-dithiobis-(2nitrobenzoic acid) (DTNB; containing $10 \mathrm{mM} / \mathrm{L}$ natrium chloride and $2 \mathrm{mM} / \mathrm{L}$ magnesium chloride). The volume of the sample was completed to $0.345 \mathrm{~mL}$ with Trishydrochloride buffer (50 mM/L, pH 8.0). Samples containing Tris-hydrochloride buffer instead of the studied samples were run in the same way. The absorbance $\left(405 \mathrm{~nm}, 22^{\circ} \mathrm{C}\right)$ was read after $30 \mathrm{~min}$. The absorbance caused by the spontaneous hydrolysis of the substrate was monitored using blank samples containing DTNB and ATCh (BTCh) completed to $0.345 \mathrm{~mL}$ with Tris-hydrochloride buffer. The absorbance originating from the blank sample was subtracted from the absorbance of the test sample. The false-positive effect of samples was tested according to the method of Rhee et al. (2003) with minor modifications, as described previously (Szwajgier and Borowiec, 2012a): after the addition of the substrate, buffer and enzyme, the sample was left for $30 \mathrm{~min}$. The test solutions followed by DTNB were then added followed by immediate measurement of the absorbance. Each sample was analysed in at least three repeats. The inhibitory activity of test compounds was expressed using eserine (Es) equivalents (nM Es/L), as proposed previously (Szwajgier and Borowiec, 2012a). A calibration curve was plotted using Es solutions $(7.1 \mathrm{nM} / \mathrm{L}-7.27 \mu \mathrm{M} / \mathrm{L})$. Results are expressed as mean values with standard deviations.

\section{RESULTS AND DISCUSSION}

Preparative chromatography with Sephadex LH-20 was the first step of isolation of cholinesterase (ChE) inhibitors from wild strawberry and apricot and for this purpose, a huge number of fractions were screened using Ellman's test (example separation of compounds from wild strawberry ultrafiltrate presented in Fig. 1). ChE

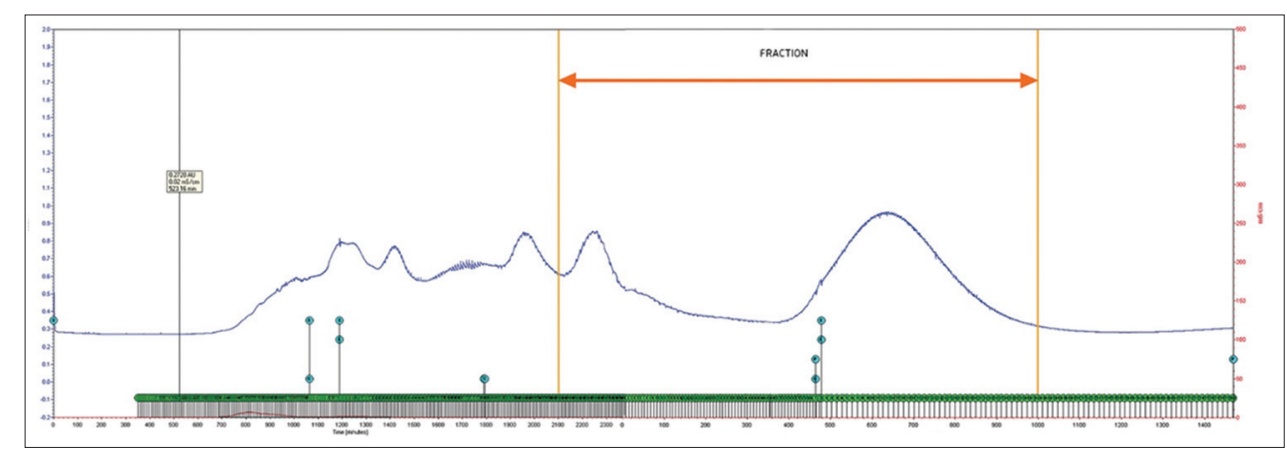

Fig 1. Example chromatogram obtained after the preparative chromatography of wild strawberry fruit ultrafiltrate (Sephadex LH-20, $280 \mathrm{~nm})$. 
inhibitors were present in fractions leaving the column in the range of $2100-3500 \mathrm{~min}$. (Fig. 1). However, in this range, active fractions were eluted alternately with inactive ones, at least as measured using Ellman's method (detailed results of analyses not given due to the limited space). Due to the risk of the loss of fractions containing inhibitors at concentrations below the detection limit of the method, we decided to gather all fractions in the range of $2100-3500 \mathrm{~min}$. followed by concentration and separation in HPLC (Fig. 2A). The same procedure was similar in the case of an ultrafiltrate from apricot fruit (Fig. 2B).

After the preparative HPLC, selected fractions (e.g. nos. 8-18 presented in Fig. 2A obtained from wild strawberry extract) exerted anti-ChE activity. Compounds present in freeze-dried fractions 8-18 were separated in analytical HPLC (Fig. 3A), but the concentration of the compound was low and the fraction was concentrated by freeze-drying and once more analysed in analytical HPLC (Fig. 3B). A chromatogram obtained in this way presents the main, completely separated peak with the retention time (RT) 54 min. that fits well with RT of the chromatographic peak of authentic quercetin standard (Fig. 4). The compound with RT 54 min. (Fig. 3B) was collected after a several dozen consecutive injections and the whole sample was freeze dried and analysed using IR spectroscopy and ${ }^{1} \mathrm{H}-\mathrm{NMR}$ spectroscopy.

Compound 1: yellow needles, $12.1 \mathrm{mg}$. IR spectrum of compound 1 was compared with IR spectra of

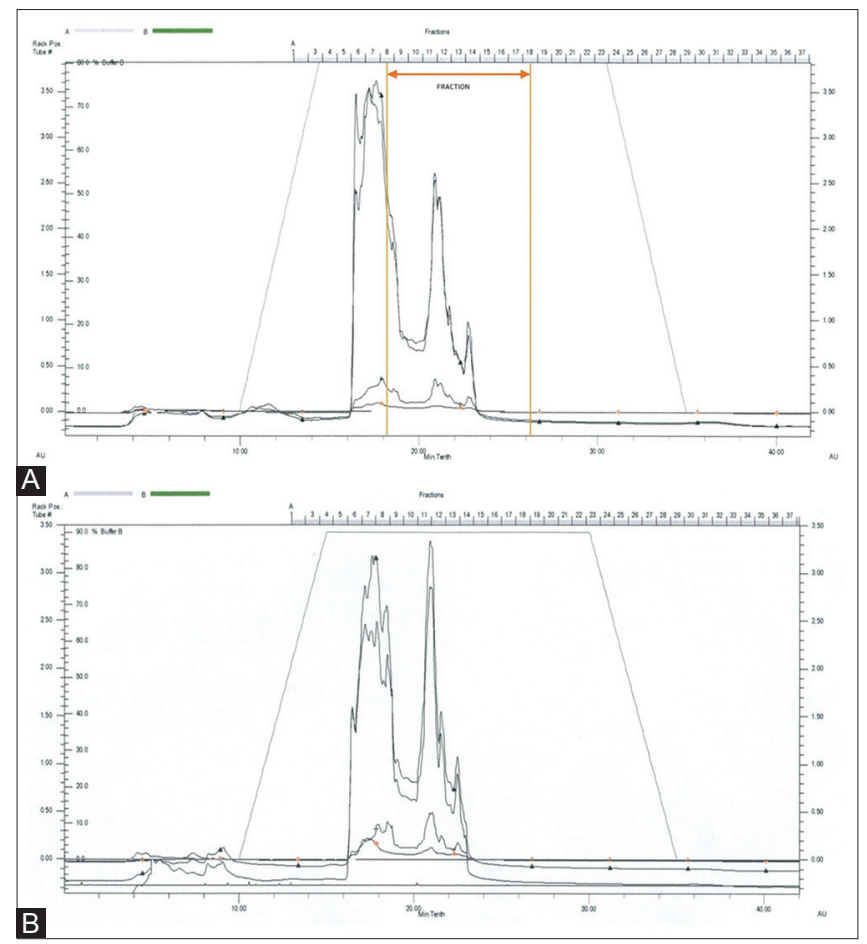

Fig 2. Example chromatograms after the preparative HPLC (RP-C18) of wild strawberry ultrafiltrate $(A)$ and apricot ultrafiltrate $(B)$. quercetin, presented in previous works (Heneczkowski et al., 2001; Olszewska and Wolbiś, 2001; Yoshioka et al., 2004; Chebil et al., 2007): OH stretched phenols, broad band $\left(3330.40 \mathrm{~cm}^{-1}, 2939.13 \mathrm{~cm}^{-1}\right), \mathrm{C}-\mathrm{H}\left(2904.54 \mathrm{~cm}^{-1}\right)$, $\mathrm{C}=\mathrm{O}$, valence band $\left(1651.13 \mathrm{~cm}^{-1}\right), \mathrm{C}=\mathrm{C}$ group of an aromatic ring $\left(1591.49 \mathrm{~cm}^{-1}\right)$, aromatic ring vibrations (1498.76 $\left.\mathrm{cm}^{-1}, 1453.85 \mathrm{~cm}^{-1}\right), \mathrm{C}-\mathrm{OH}$ deformation vibrations $\left(1357.88 \mathrm{~cm}^{-1}\right), \mathrm{C}-\mathrm{O}-\mathrm{C}$ stretching vibrations $\left(1168.69 \mathrm{~cm}^{-1}\right), \mathrm{C}-\mathrm{O}$ stretching multiplet in the range of $1300-1000 \mathrm{~cm}^{-1}\left(1060.09 \mathrm{~cm}^{-1}, 1039.95 \mathrm{~cm}^{-1}\right), \mathrm{C}=\mathrm{C}$ in aromatic ring $\left(832.48 \mathrm{~cm}^{-1}, 806.72 \mathrm{~cm}^{-1}\right)$ (Fig. 5). Similarly, quercetin isolated from apricot fruit extract was identified in the same manner using IR spectroscopy (Fig. 6).

${ }^{1} \mathrm{H}-\mathrm{NMR}$ analysis of the compound 1 revealed following information (Fig. 7): $7.72 d\left(2.2 \mathrm{~Hz}, \mathrm{H}-2^{\prime}\right), 7.62 d d(8.5$ and $2.2 \mathrm{~Hz}, \mathrm{H}-6$ ) $, 6.87 d\left(8.5 \mathrm{~Hz}, \mathrm{H}-5^{\prime}\right), 6.37 d(2.1 \mathrm{~Hz}, \mathrm{H}-8)$, $6.17 d(2.1 \mathrm{~Hz}, \mathrm{H}-6)$ confirmed that the studied compound was quercetin. Similarly, quercetin isolated from apricot fruit extract was identified in the same manner using ${ }^{1}$ H-NMR (Fig. 8).

First, it is worth mentioning that extracts from wild strawberry fruit and selected Prunus sp. fruits demonstrated effective anti-AChE and anti-BChE activities (Szwajgier and

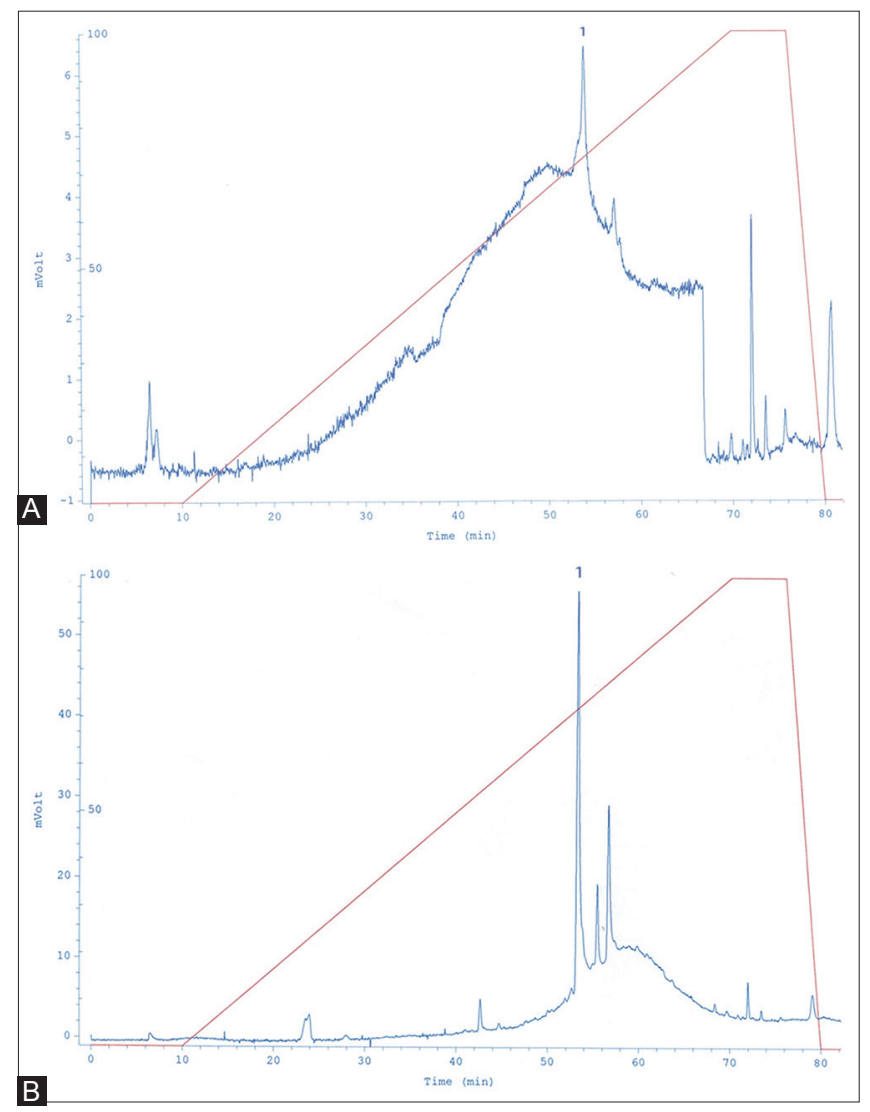

Fig 3. Separation of compounds from wild strawberry extract (see Fig. 2A) before (A) and after concentration (B). Peak 1 (RT 54 min.) represents quercetin as a main compound. 


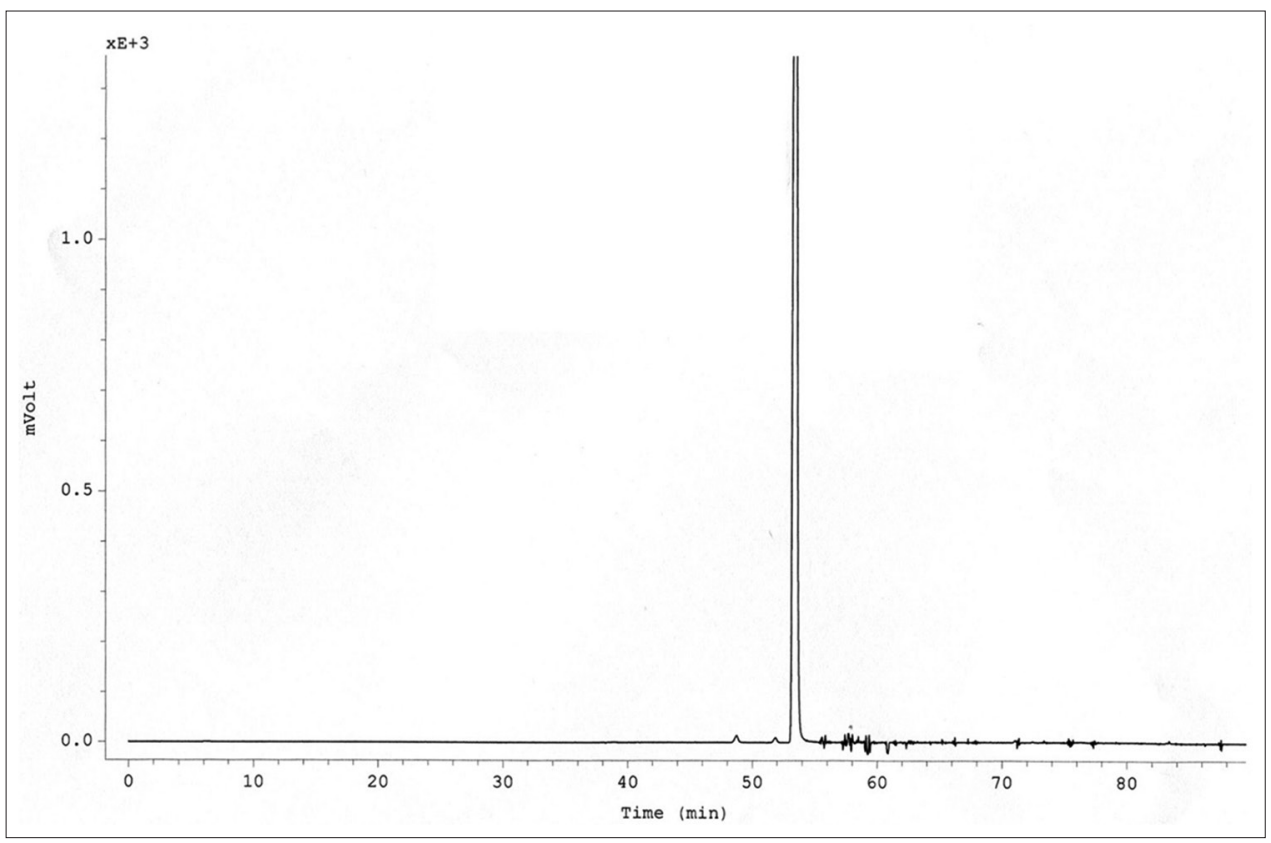

Fig 4. Authentic HPLC standard of quercetin.

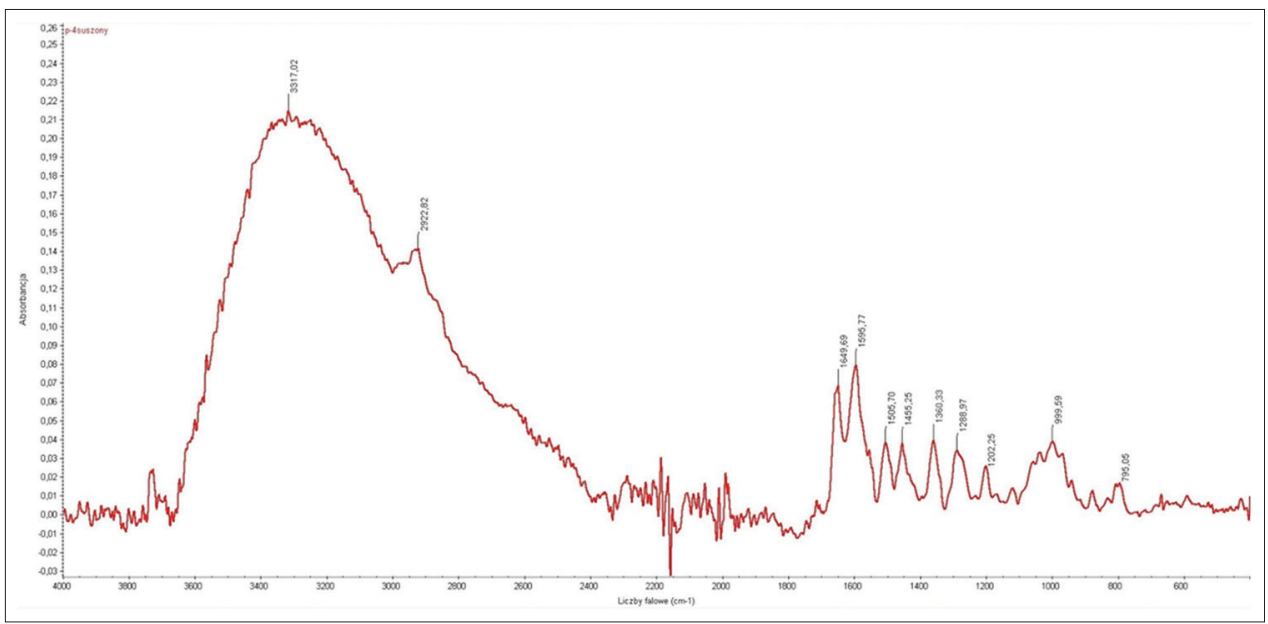

Fig 5. IR spectrum of compound 1 from wild strawberry (peak 1 with RT 54 min. presented in Fig. 3.).

Borowiec, 2012b). In the presented work, activity-guided purification revealed that quercetin was the most efficient cholinesterase inhibitor in wild strawberry and apricot fruit extract, among all polyphenolic compounds, as the purification procedure strongly promoted this group of bioactive compounds. Quercetin is found in many fruits (apples, cherries and berries) and vegetables (onions, asparagus, red leaf lettuce, tomatoes, peas, broccoli and green peppers) (Costa et al., 2016). It can be stated that both studied fruits are a rich source of quercetin. Wang and Lewers (2007) identified quercetin 3-glucoside and quercetin 3 -glucuronide in wild strawberry fruit. Besides quercetin, kaempferol, myricetin and ellagic acid were also identified in considerable levels in wild strawberry fruit by Milivojević et al. (2011). The content of quercetin in wild strawberry is between $0.007-0.02 \mu \mathrm{M} / \mathrm{g}$ fresh weight (FW) (Peñarrieta et al., 2009) and $7.34 \pm 0.24 \mu \mathrm{g} / \mathrm{g}$ FW (Milivojević et al., 2011). The dominant glycosides of quercetin in wild strawberry are glucoside $(4.1 \pm 0.42 \mathrm{mg} / \mathrm{kg} \mathrm{FW})$ and galactoside $(2.6 \pm 0.24 \mathrm{mg} / \mathrm{kg} \mathrm{FW})$ (Mikulic-Petkovsek et al., 2012).

Similarly, Ruiz et al. (2005) showed that apricot fruit is a source of quercetin. The authors identified a number of phenolic compounds in apricot fruit, including quercetin glycosides (quercetin 3-rutinoside, quercetin 3-hexoside and quercetin 3-acetylhexoside). Also, Dragovic-Uzelac et al. (2005a) detected quercetin 3-rutinoside in apricot at $26.36 \mathrm{mg} / \mathrm{kg}$ of investigated samples. Then, the amount of three quercetin glycosides in the different 


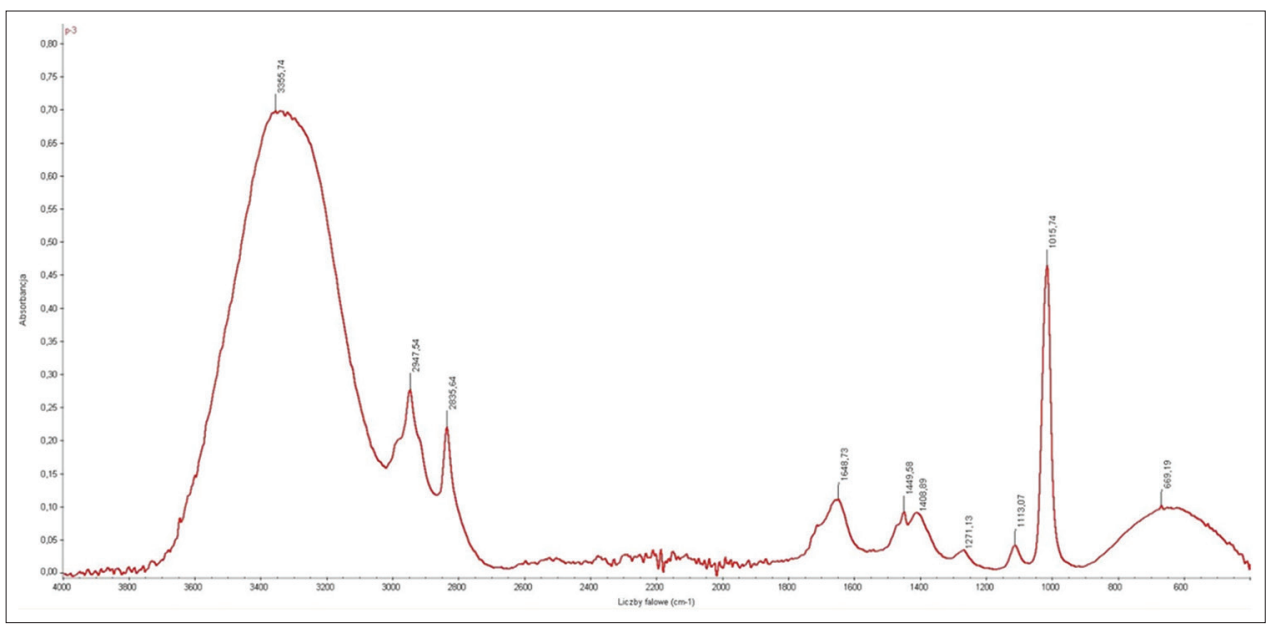

Fig 6. IR spectrum of quercetin isolated from apricot fruit extract.

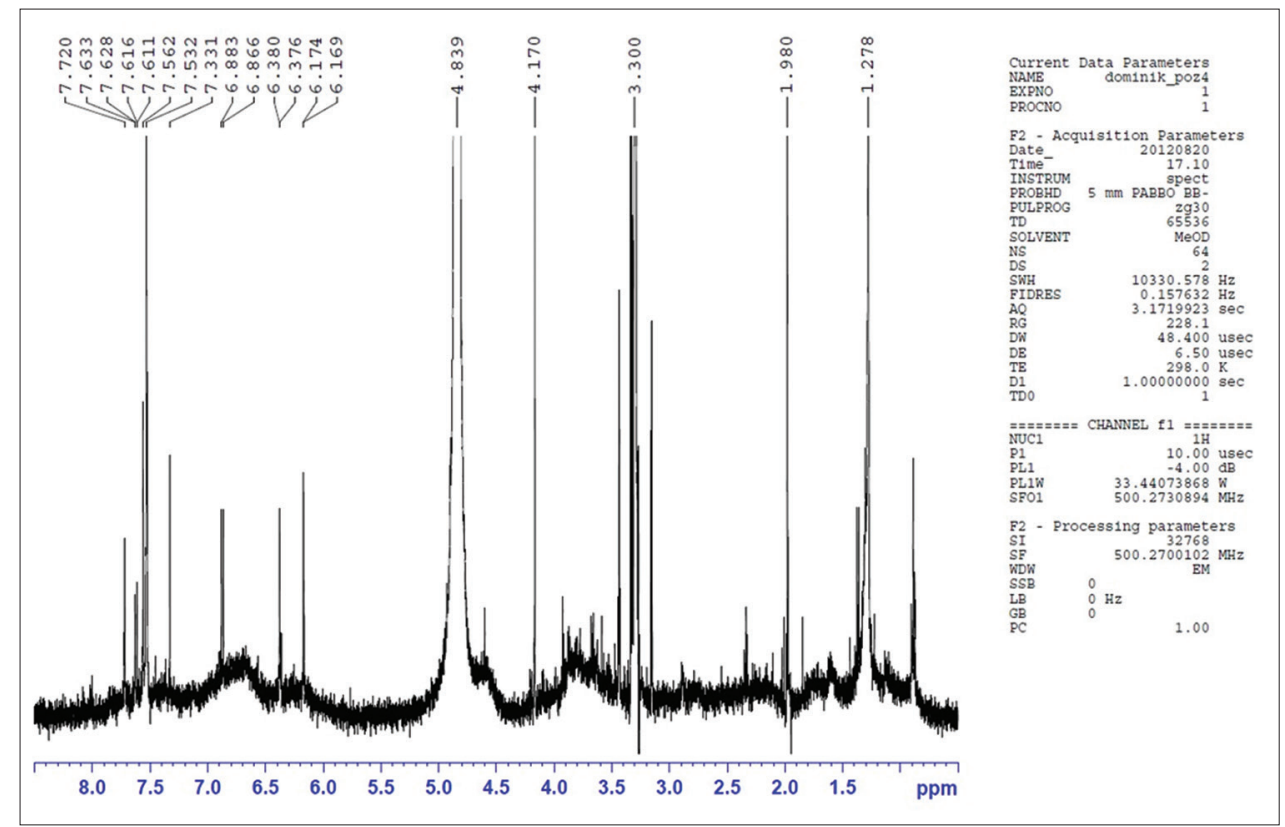

Fig 7. ${ }^{1} \mathrm{H}-\mathrm{NMR}$ spectrum of compound 1 (peak 1 with RT 54 min. presented in Fig. 3.).

stages of maturity of apricots (from three cultivars and two geographical regions) was determined (DragovicUzelac et al., 2007). Generally, quercetin 3-galactoside, quercetin 3-rutinoside and quercetin 3-glucoside were detected in higher amounts in apricot fruit at the beginning $(5.47 \pm 1.92-13.96 \pm 1.36,17.73 \pm 1.34-42.83 \pm 1.62$ and $8.12 \pm 1.02-28.49 \pm 4.03 \mathrm{mg} / \mathrm{kg}$ of examined sample, respectively) and at the end of ripening (5.38 $\pm 0.79-9.03$ $\pm 1.43,12.55 \pm 0.68-40.73 \pm 1.40$ and $6.55 \pm 0.86-$ $15.08 \pm 1.47 \mathrm{mg} / \mathrm{kg}$ of examined sample, respectively). But, the content of quercetin 3-galactoside, quercetin 3 -rutinoside and quercetin 3-glucoside was slightly decreased at the semi-mature stage of fruit $(2.76 \pm 1.01$ $-8.79 \pm 1.62,9.61 \pm 0.36-31.94 \pm 1.42$ and $6.98 \pm 0.75$ $-13.11 \pm 1.95 \mathrm{mg} / \mathrm{kg}$ of examined sample, respectively). Fan et al. (2018) identified quercetin 3-rutinoside in the full mature peels $(30.2 \pm 3.5-102.7 \pm 6.8 \mathrm{mg} / 100 \mathrm{FW})$ and pulps $(0.3 \pm 0.5-0.9 \pm 0.2 \mathrm{mg} / 100 \mathrm{FW})$ of apricots.

First of all, quercetin is a valuable anti-oxidant and antiinflammatory agent (Lesjak et al., 2018). Secondly, quercetin has been suggested for the treatment of AD (Bui and Nguyen, 2017) and a comprehensive review discusses the anti-AChE and anti-BChE activity of quercetin (Khan et al., 2009; Anand and Singh, 2013). In particular, Orhan et al. (2007) pointed out quercetin as a substantially more efficient AChE inhibitor than a number of well-known polyphenolic compounds (luteolin-7-O-rutinoside, chlorogenic acid, caffeic acid, gallic acid, apigenin, genistein, kaempferolgalactoside, naringin, diosmin, silibinin, silymarin). The above-mentioned facts have been widely confirmed by other authors recently (Jabir et al., 2018; Khaw et al., 2018). 


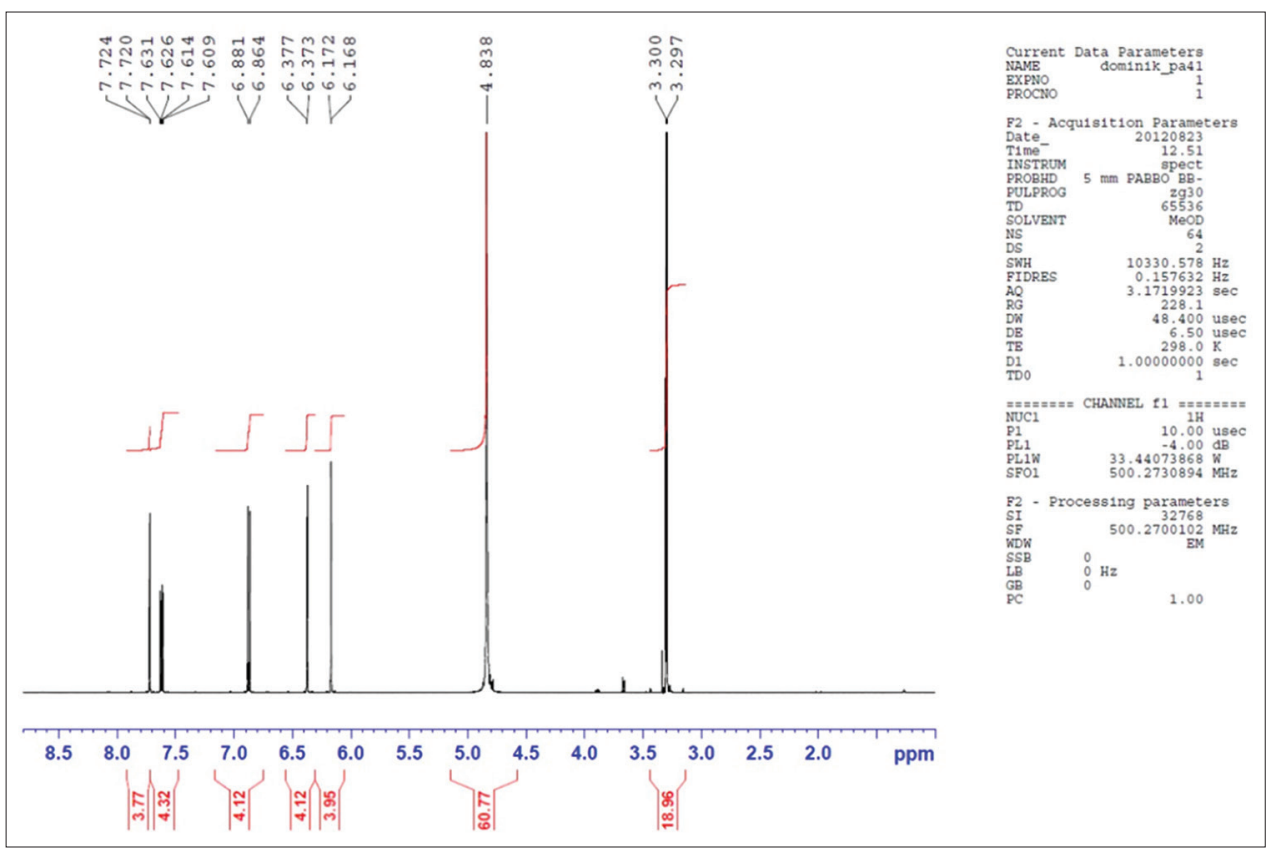

Fig 8. ${ }^{1} \mathrm{H}-\mathrm{NMR}$ spectrum of quercetin isolated from apricot fruit extract.

De Oliveira et al. (2018) also identified quercetin and gallic acid as ChE inhibitors in ethyl acetate fraction from Caryocar brasiliense using liquid chromatography - mass spectrometry technique and Ellman's colorimetric method. Findings in the next study (Zahoor et al., 2018) agree with the abovementioned and our results where plant extracts have been reported to possess $\mathrm{ChE}$ inhibitory properties, and these inhibitory effects have been largely associated to their constituent phenolics. Quercetin and mandelic acid were isolated by Zahoor et al. (2018) from ethyl acetate fraction from Aesculus indica fruit using the HPLC method and characterised by Fourier transform infrared spectroscopy (FTIR) and the NMR technique. Additionally, Omar et al. (2018) also proved not only anti-AChE $\left(\mathrm{IC}_{50}: 55.44 \mu \mathrm{M}\right)$ and anti-BChE $\left(\mathrm{IC}_{50}: 19.08 \mu \mathrm{M}\right)$ activity by quercetin but also its inhibitory activity against tyrosinase $\left(\mathrm{IC}_{50}: 10.73 \mu \mathrm{M}\right)$ and histone deacetylase $\left(\mathrm{IC}_{50}: 105.1 \mu \mathrm{M}\right)$, the enzymes involved in the pathogenesis of $\mathrm{AD}$. Additionally, it is known that not only quercetin but also its glycosides are sufficient AChE inhibitors and anti-AChE activity is ranged from $\mathrm{IC}_{50} 36.47 \mu \mathrm{M}$ (quercetin-3-O-(2",6"-di-acetyl)-glucoside) to $\mathrm{IC}_{50} 94.92 \mu \mathrm{M}$ (quercetin-3-O-(2",6"-di-rhamnosyl)glucoside) (Olennikov et al., 2017).

The above discussed raw sources of quercetin could be considered for purification of this ChE inhibitor on an industrial scale. In this case, the cost-effectiveness of the process is significant. However, our goal was to identify the most effective inhibitors in selected fruit sources using activity-guided purification. Therefore, we presented the qualitative and not the quantitative approach. Comparison between our work and works of other authors is difficult.
Although the quercetin level has been previously determined in many works, as discussed above, no works concerning the purification of quercetin from these sources in order to evaluate the efficiency of the purification process are available.

\section{CONCLUSIONS}

Due to a suitable chromatographic method for the isolation of selected flavonoids from wild strawberry and apricot fruits, proposed in this work, we have identified main phenolic ChE inhibitor: quercetin. Wild strawberry and apricot fruits are a promising natural source of $\mathrm{ChE}$ inhibitors (including quercetin and other polyphenols) more interesting than synthetic ones because of their availability, cost-effectiveness and lesser toxicity. In addition, the proposed purification procedure can be adopted for the isolation of phenolic $\mathrm{ChE}$ inhibitors from other fruits from the Rosaceae family.

\section{Author's contributions}

In this research, all authors contributed effectively. Dominik Szwajgier designed and achieved experiments and wrote the paper; Kamila Borowiec performed research and wrote the paper; Josef Zapp performed research and analyzed the data.

\section{REFERENCES}

Anand, P. and B. Singh. 2013. Flavonoids as lead compounds modulating the enzyme targets in Alzheimer's disease. Med. Chem. Res. 22: 3061-3075. 
Bui, T. T. and T. H. Nguyen. 2017. Natural product for the treatment of Alzheimer's disease. J. Basic Clin. Physiol. Pharmacol. 28: 413-423.

Cao, G., R. M. Russell, N. Lischner and R. L. Prior. 1998. Serum antioxidant capacity is increased by consumption of strawberries, spinach, red wine or Vitamin C in elderly women. J. Nutr. 128: 2383-2390.

Carlton, P. S., L. A. Kresty, J. C. Siglin, M. A. Morse, J. Lu, C. Morgan and G. D. Stoner. 2001. Inhibition of N-nitrosomethylbenzylamineinduced tumorigenesis in the rat esophagus by dietary freezedried strawberries. Carcinogenesis. 22: 441-446.

Chebil, L., J. Anthoni, C. Humeau, C. Gerardin, J. M. Engasser and M. Ghoul. 2007. Enzymatic acylation of flavonoids: Effect of the nature of the substrate, origin of lipase, and operating conditions on conversion yield and regioselectivity. J. Agric. Food Chem. 55: 9496-9502.

Cheel, J., C. Theoduloz, J. A. Rodriguez, P. D. S. Caligari and G. Schmeda-Hirschmann. 2007. Free radical scavenging activity and phenolic content in achenes and thalamus from Fragaria chiloensis ssp. Chiloensis, F. vesca and F. $x$ ananassa cv. Chandler. Food Chem. 102: 36-44.

Costa, L. G., J. M. Garrick, P. J. Roquè and C. Pellacani. 2016. Mechanisms of neuroprotection by quercetin: Counteracting oxidative stress and more. Oxid. Med. Cell. Longev. 2016: 2986796.

De Oliveira, T. S., D. V. Thomaz, H. F. Da Silva Neri, L. B. Cerqueira, L. F. Garcia, H. P. V. Gil, R. Pontarolo, F. R. Campos, E. A. Costa, F. C. A. Dos Santos, E. De Souza Gil and P. C. Ghedini. 2018. Neuroprotective effect of Caryocar brasiliense Camb. leaves is associated with anticholinesterase and antioxidant properties. Oxid. Med. Cell. Longev. 2018: 9842908.

Dos Santos Picanco, L. C., P. F. Ozela, M. de Fatima de Brito Brito, A. A. Pinheiro, E. C. Padilha, F. S. Braga, C. H. T. de Paula da Silva, C. B. R. Dos Santos, J. M. C. Rosa and L. I. da Silva Hage-Melim. 2018. Alzheimer's disease: A review from the pathophysiology to diagnosis, new perspectives for pharmacological treatment. Curr. Med. Chem. 25: 3141-3159.

Doumett, S., D. Fibbi, A. Cincinelli, E. Giordani, S. Nin and M. Del Bubba. 2011. Comparison of nutritional and nutraceutical properties in cultivated fruits of Fragaria vesca L. produced in Italy. Food Res. Int. 44: 1209-1216.

Dragovic-Uzelac, V., B. Levaj, V. Mrkic, D. Bursac and M. Boras. 2007. The content of polyphenols and carotenoids in three apricot cultivars depending on stage of maturity and geographical region. Food Chem. 102: 966-975.

Dragovic-Uzelac, V., J. Pospišil, B. Levaj and K. Delonga. 2005a. The study of phenolic profiles of raw apricots and apples and their purees by HPLC for the evaluation of apricot nectars and jams authenticity. Food Chem. 91: 373-383.

Dragovic-Uzelac, V., K. Delonga, B. Levaj, S. Djakovic and J. Pospišil. 2005b. Phenolic profiles of raw apricots, pumpkins, and their purees in the evaluation of apricot nectar and jam authenticity. J. Agric. Food Chem. 53: 4836-4842.

Ellman, G. L., D. K. Lourtney, V. Andres and G. A. Gmelin. 1961. New and rapid colorimetric determination of acetylcholinesterase activity. Biochem. Pharmacol. 7: 88-95.

Fan, X., W. Jiao, X. Wang, J. Cao and W. Jiang. 2018. Polyphenol composition and antioxidant capacity in pulp and peel of apricot fruits of various varieties and maturity stages at harvest. Int. J. Food Sci. Technol. 53: 327-336.

Folin, O. and V. Ciocalteu. 1927. On tyrosine and tryptophane determination in proteins. J. Biol. Chem. 73: 627-650.

Heneczkowski, M., M. Kopacz, D. Nowak and A. Kuźniar. 2001.
Infrared spectrum analysis of some flavonoids. Acta Pol. Pharm. 58: 415-420.

Jabir, N. R., F. R. Khan and S. Tabrez. 2018. Cholinesterase targeting by polyphenols: A therapeutic approach for the treatment of Alzheimer's disease. CNS Neurosci. Ther. 24: 753-762.

Khan, M. T. H., I. Orhan, F. S. Şenol, M. Kartal, B. Şener, M. Dvorská, K. Šmejkal and T. Šlapetová. 2009. Cholinesterase inhibitory activities of some flavonoid derivatives and chosen xanthone and their molecular docking studies. Chem. Biol. Interact. 181: 383-389.

Khaw, K.Y., V. Murugaiyah, M. Khairuddean and W.N. Tan. 2018. Garcinexanthone G, a selective butyrylcholinesterase inhibitor from the stem bark of Garcinia atroviridis. Nat. Prod. Sci. 24: 88-92.

Lesjak, M., I. Beara, N. Simin, D. Pintać, T. Majkić, K. Bekvalac, D. Orčić and N. Mimica-Dukić. 2018. Antioxidant and antiinflammatory activities of quercetin and its derivatives. J. Funct. Foods. 40: 68-75

Mikulic-Petkovsek, M., A. Slatnar, F. Stampar and R. Veberic. 2012. HPLC-MSn identification and quantification of flavonol glycosides in 28 wild and cultivated berry species. Food Chem. 135: 2138-2146.

Milivojević, J., V. Maksimović, M. Nikolić, J. Bogdanović, R. Maletić and D. Milatović. 2011. Chemical and antioxidant properties of cultivated and wild Fragaria and Rubus berries. J. Food Qual. 34: 1-9.

Olennikov, D. N., N. I. Kashchenko, N. K. Chirikova, A. Akobirshoeva, I. N. Zilfikarov and C. Vennos. 2017. Isorhamnetin and quercetin derivatives as anti-acetylcholinesterase principles of marigold (Calendula officinalis) flowers and preparations. Int. J. Mol. Sci. 18: E1685.

Olszewska, M. and M. Wolbiś. 2001. Flavonoids from the flowers of Prunus spinosa L. Acta Pol. Pharm. 58: 367-372.

Omar, S. H., C. J. Scott, A. S. Hamlin and H. K. Obied. 2018. Biophenols: Enzymes ( $\beta$-secretase, cholinesterases, histone deacetylase and tyrosinase) inhibitors from olive (Olea europaea L.). Fitoterapia. 128: 118-129.

Orhan, I., M. Kartal, F. Tosun and B. Şener. 2007. Screening of various phenolic acids and flavonoid derivatives for their anticholinesterase potential. Z. Naturforsch. C. 62: 829-832.

Pawlaczyk, I., L. Czerchawski, W. Pilecki, E. Lamer-Zarawska and R. Gancarz. 2009. Polyphenolic-polysaccharide compounds from selected medicinal plants of Asteraceae and Rosaceae families: Chemical characterization and blood anticoagulant activity. Carbohydr. Polym. 77: 568-575.

Peñarrieta, J. M., J. A. Alvarado, B. Bergenståhl and B. Ákesson. 2009. Total antioxidant capacity and content of phenolic compounds in wild strawberries (Fragaria vesca) collected in Bolivia Int. J. Fruit Sci. 9: 344-359.

Rao, A. A., G. R. Sridhar and U. N. Das. 2007. Elevated butyrylcholinesterase and acetylcholinesterase may predict the development of type 2 diabetes mellitus and Alzheimer's disease. Med. Hypotheses. 69: 1272-1276.

Rhee, I. K., R. M. van Rijn and R. Verpoorte. 2003. Qualitative determination of false-positive effects in the acetylcholinesterase assay using thin layer chromatography. Phytochem. Anal. 14: 127-131.

Roussos, P. A., V. Sefferou, N.K. Denaxa, E. Tsantili and V. Stathis. 2011. Apricot (Prunus armeniaca L.) fruit quality attributes and phytochemicals under different crop load. Sci. Hortic. 129: $472-478$

Ruiz, D., J. Egea, M. I. Gil and F. A. Tomas-Barberan. 2005. 
Characterization and quantitation of phenolic compounds in new apricot (Prunus armenica L.) varieties. J. Agric. Food Chem. 53: 9544-9552.

Scalzo, J., A. Politi, N. Pellegrini, B. Mezzetti and M. Battino. 2005. Plant genotype affects total antioxidant capacity and phenolic contents in fruit. Nutrition. 21: 207-213.

Sondheimer, E. and C. B. Karash. 1956. The major anthocyanin pigments of the wild strawberry (Fragaria vesca). Nature. 178: 648-649.

Szwajgier, D. and K. Borowiec. 2012a. Phenolic acids from malt are efficient acetylcholinesterase and butyrylcholinesterase inhibitors. J. Inst. Brew. 118: 40-48.

Szwajgier, D. and K. Borowiec. 2012b. Screening for cholinesterase inhibitors in selected fruits and vegetables. Electron. J. Pol. Agric. Univ. 15: 1-6.

Wang, S. Y. and K. S. Lewers. 2007. Antioxidant capacity and flavonoid content in wild strawberries. J. Am. Soc. Hortic. Sci. 132: 629-637.

Wedge, D. E., K. M. Meepagala, J. B. Magee, S. H. Smith, G. Huang and L. L. Larcom. 2001. Anticarcinogenic activity of strawberry, blueberry, and raspberry extracts to breast and cervical cancer cells. J. Med. Food. 4: 49-51.

Whitehouse, P. J., D. L. Price, A. W. Clark, J. T. Coyle and M. R. DeLong. 1981. Alzheimer's disease: Evidence for selective loss of cholinergic neurons in the nucleus basalis. Ann. Neurol. 10: 115-126.

Yoshioka, T., T. Inokuchi, S. Fujioka and Y. Kimura. 2004. Phenolic compounds and flavonoids as plant growth regulators from fruit and leaf of Vitex rotundifolia. Z. Naturforsch. C. 59: 509-514.

Zahoor, M., S. Shafiq, H. Ullah, A. Sadiq and F. Ullah. 2018. Isolation of quercetin and mandelic acid from Aesculus indica fruit and their biological activities. BMC Biochem. 19: 5. 